\title{
Effects of prostaglandins on cultured granulosa cells from rhesus monkeys
}

\author{
K. G. Gould, C. E. Graham and D. C. Collins \\ Yerkes Regional Primate Research Center, and Department of Medicine, \\ Emory University, Atlanta, Georgia 30322, U.S.A.
}

It has repeatedly been demonstrated that administration of prostaglandin (PG) F-2 $\alpha$ to nonprimates is luteolytic and inhibits progesterone synthesis, while administration of PGE-2 stimulates progesterone synthesis. The luteolytic effect of PGF- $2 \alpha$ has not been conclusively demonstrated $i n$ vivo in the primate, variable effects on the circulating progesterone levels having been reported (Shaikh, 1972; Auletta, Speroff \& Caldwell, 1973; Shaikh \& Klaiber, 1974; Korda, Shutt, Smith, Shearman \& Lyneham, 1975; Lyneham, Korda, Shutt, Smith \& Shearman, 1975). PGE-2 has been reported to increase progesterone synthesis by the primate corpus luteum (Channing, 1971). It is becoming apparent that route of administration, dosage and other unknown factors can alter the effect of PGF-2 $\alpha$ on progesterone synthesis (Channing, 1972; Auletta et al., 1973; Puri \& Laumas, 1975; Henderson \& McNatty, 1975). Attempts to isolate the factors whereby PGs affect granulosa cells by the use of in-vitro systems have met with limited success, because PGs in vitro frequently exhibit effects which differ from those seen in vivo (Lindner et al., 1974). We therefore examined the effect of the developmental state of the follicle on its response to PG and dibutyryl cyclic AMP in vitro. Dibutyryl cyclic AMP (dbcAMP) is considered to mimic the action of gonadotrophins, because synthesis of its analogue, cAMP, is believed to be a step in the intracellular action of gonadotrophins (Marsh, 1976).

\section{Methods}

The rhesus monkeys (Macaca mulatta) were premenarchal females weighing $3-4 \cdot 5 \mathrm{~kg}$ and adults. They each received a daily i.m. injection of 500 i.u. PMSG (Gestyl: Organon) for 5 days before bilateral ovariectomy. The follicles were incised under Ham's F10 medium. Cells which were readily extruded from the follicle were considered to represent a pure granulosa population: these cells were separated by agitation in F10 medium and washed in three changes of medium before culture in Ham's F10 with $15 \%$ agamma calf serum and antibiotics. Absence of FSH, LH and steroid hormones in the media was confirmed by radioimmunoassay of the medium samples before use.

Medium was recovered at $24-\mathrm{h}$ intervals and stored at $-20^{\circ} \mathrm{C}$ before assay for progesterone. After a 24-h period for establishment of a monolayer the cultures were maintained for a 'base' period of $24 \mathrm{~h}$, with or without dbcAMP in the medium. Progesterone output during this period was compared with that during the subsequent $24-\mathrm{h}$ 'test' period in which various hormones were present in the medium. All variations in medium were tested in triplicate within each experiment.

PGF-2 $\alpha$ (THAM salt) and PGE-2 were supplied by the Upjohn Co. and aqueous solutions $(10 \mathrm{mg} / \mathrm{ml})$ were prepared $<24 \mathrm{~h}$ before use. The dbcAMP was dissolved in F10 solution and added to the culture medium before use. The final concentrations in the culture media were $5 \mu \mathrm{g} \mathrm{PG} / \mathrm{ml}$ and $8 \mu \mathrm{g} \mathrm{dbcAMP} / \mathrm{ml}$.

Progesteroneassay. The radioimmunoassay procedure was adapted from that previously described for the assay of oestradiol-17 $\beta$ in our laboratory (Wright, Robinson, Collins \& Preedy, 1973). The antiserum was obtained from rabbits immunized with progesterone-11 $\alpha$-succinyl-bovine serum albumin as previously described (Thorneycroft \& Stone, 1972). The $\left[1,2,6,7-{ }^{3} \mathrm{H}\right]$ progesterone (sp.act. $85 \mathrm{Ci} / \mathrm{mmol}$ ) was obtained from New England Nuclear (Boston, Massachusetts).

Progesterone levels were measured in the media without extraction or chromatography. Aliquots of $0.1 \mathrm{ml}$ (usually diluted $10-1000$ times with phosphate-saline buffer) were taken and added to the test tubes for assay. Identical samples from the same batch of media but not used for the cell 
cultures were added to the standard curve which gave precise measurements over the range of 0.10 to $0.75 \mathrm{ng}$. The intra-assay coefficient of variation was $6.4 \%$ for a $42 \mathrm{ng} / \mathrm{ml} \mathrm{sample}$ and $8.6 \%$ for a $986 \mathrm{ng} / \mathrm{ml}$ sample. The interassay coefficients of variation were $9.3 \%$ and $11.9 \%$ respectively for the low and high samples.

Progesterone levels were calculated in 9 samples of media after direct radioimmunoassay as described above and after petroleum ether extraction followed by radioimmunoassay. Values ranged from 0.3 to $9.5 \mathrm{ng} / \mathrm{ml}$ for progesterone. There was significant linear regression with a regression coefficient of $1.11($ S.E. $=0.17)$ and an intercept of $-0.33($ S.E. $=1 \cdot 16)$, indicating the comparability of the values determined by the two methods.

\section{Results and discussion}

Effect of PMSG on ovarian morphology. The amount of PMSG given did not induce ovulation. The ovaries in all animals were enlarged to approximately $1.5 \mathrm{~cm}$ in the greatest dimension. In immature animals 1 or 2 follicles of approximately $4 \mathrm{~mm}$ diameter were observed in addition to several smaller follicles. In mature animals $4-5$ follicles of about $6 \mathrm{~mm}$ diameter were present with a number of smaller follicles, but there were no preovulatory follicles $(6-10 \mathrm{~mm}$ diameter). Three groups of cells were cultured: (a) from follicles $2-3 \mathrm{~mm}$ in diameter (small follicles) in ovaries from immature animals; (b) from follicles $2-3 \mathrm{~mm}$ in diameter (small follicles) in ovaries of mature animals; and (c) from follicles $3-6 \mathrm{~mm}$ in diameter (medium-sized follicles) in mature animals.

Culture characteristics. Under our culture conditions, cell attachment and formation of a monolayer took 12-24 h. Initial adhesion of cells to the substrate was observed as early as 30 min after inoculation. In most cultures, a 50-100\% confluent monolayer was established. Despite our efforts to select a uniform population of cells for culture, several morphological types were evident after $24 \mathrm{~h}$ in culture, ranging from fibroblastic to very large epithelioid types (diameter $70 \mu \mathrm{m}$ ). Cultures given

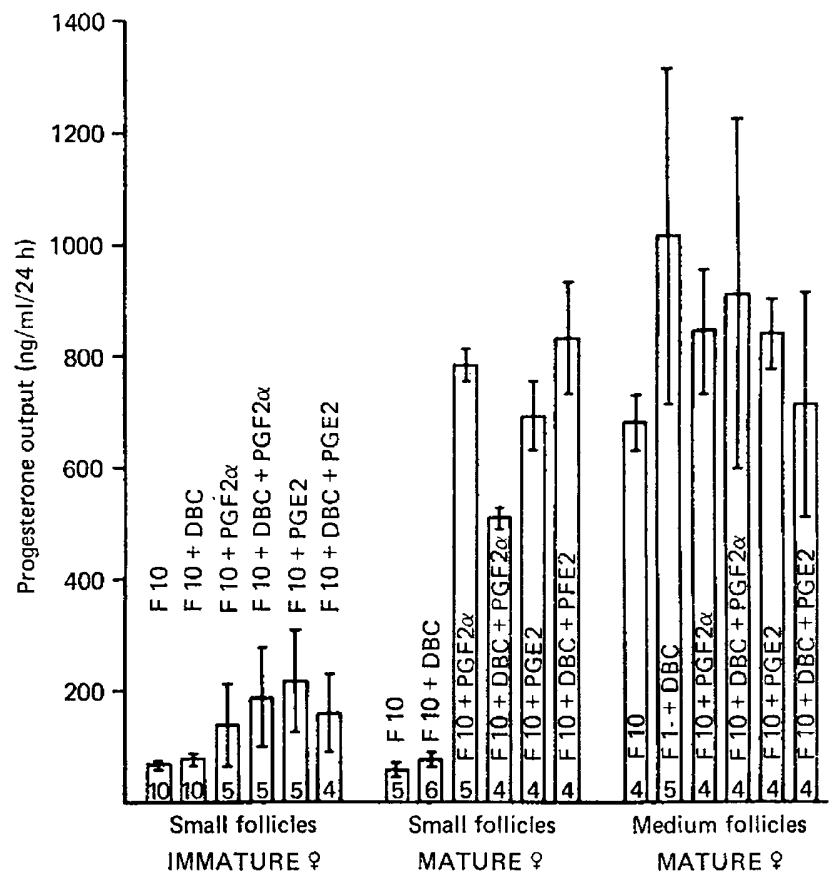

Text-fig. 1. The output (mean \pm S.E.M.) of progesterone between 48 and $72 \mathrm{~h}$ of culture by cells recovered from different classes of follicle from rhesus monkeys. F10 = Ham's F10 culture medium; DBC = dibutyryl cyclic AMP; PGF2 $\alpha=$ prostaglandin F-2 $\alpha$; PGE2 = prostaglandin E-2. The number at the base of each column represents the number of experiments. 


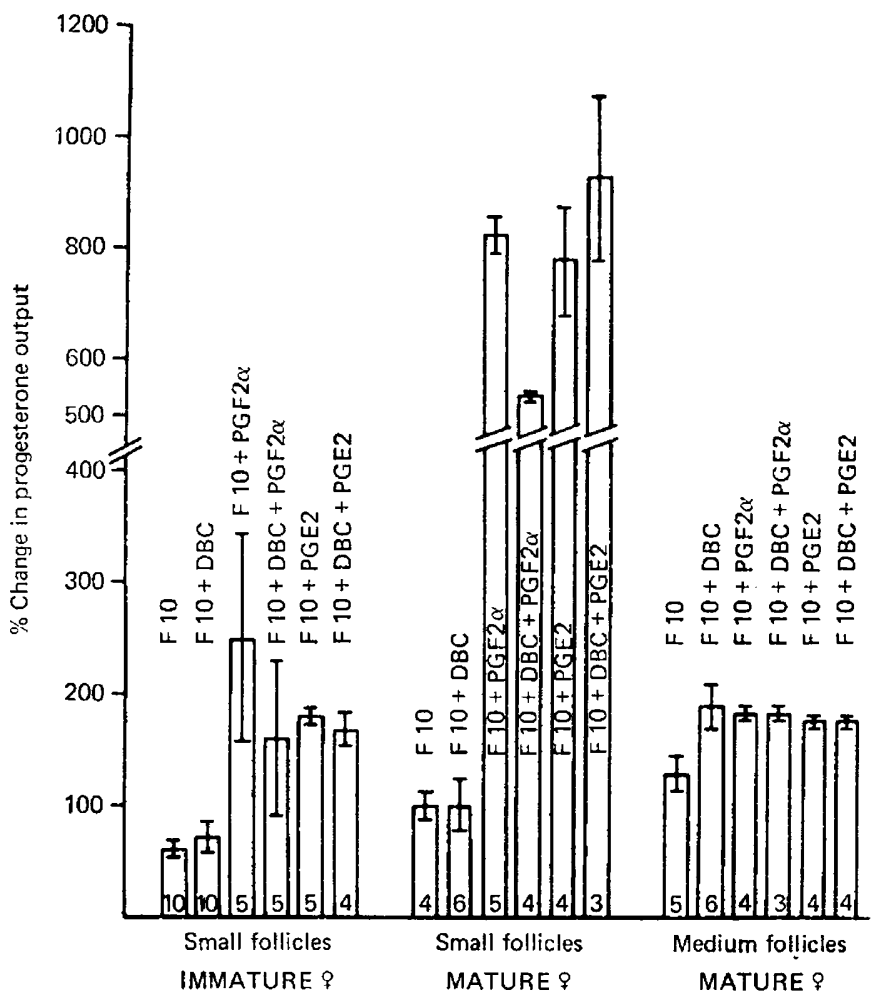

Text-fig. 2. The percentage change (mean \pm S.E.M.) in the output of progesterone between 48 and $72 \mathrm{~h}$ of culture compared with that between 24 and 48 h. Abbreviations as in Text-fig. 1.

similar stimuli secreted similar amounts of progesterone, irrespective of the proportions of each morphological cell type present. This would suggest that the steroid-secreting capacity of granulosa cells is not closely correlated with the cell shape assumed in vitro.

To demonstrate the gross secretory activity of cells of different origins and subjected to different treatments, we have expressed the data as progesterone output $/ \mathrm{ml}$ during the $48-72 \mathrm{~h}$ interval after establishment of the culture. Cultures derived from the immature animals were most variable in absolute progesterone output, with or without stimulation. In general, the absolute progesterone output was least in cultures derived from immature animals and greatest in cultures derived from larger follicles (3-6 mm) of mature animals (Text-fig 1). The progesterone output, expressed on a per cell basis, varied between $0.1 \mathrm{pg} / 24 \mathrm{~h}$ for unstimulated cells from small follicles of immature animals and $30 \mathrm{pg} / 24 \mathrm{~h}$ for PG-stimulated cells from medium-sized follicles of mature females.

The evaluation of the amount of progesterone secreted into the medium in the 24-h base period and in the following 24-h test period with added PGs or dbcAMP provided an accurate comparison of the effects of different treatments, which was essentially independent of differences in biomass between cultures. The mean progesterone output of the test period ( $\%$ change) is an accurate measure of the effect of the added agents in the test period (Text-fig. 2).

The output of progesterone by the cells from small follicles of immature or mature females was low in the absence of PGs or dbcAMP. PGs had an immediate, but limited, steroidogenic effect on cultures from immature females (progesterone output increased 4-fold) compared to the immediate, and greater, effect on cultures from small follicles of mature females (progesterone output increased 10-16-fold).

By contrast, cells from the larger follicles of mature animals had developed a capacity for spontaneous luteinization, as shown by a higher initial rate of progesterone secretion in vitro. Because of 
this high initial progesterone output, stimulation resulted in a less dramatic augmentation of progesterone secretion compared with that for small follicles, although the final concentration of progesterone was higher.

Although PGs prompted increased progesterone output within $24 \mathrm{~h}$ in all cultures, dbcAMP did not have an immediate effect in cultures derived from small follicles. Progesterone output was increased $(P<0.004) 48-72 \mathrm{~h}$ after dbcAMP stimulus (i.e. 96-120 h of culture). Such an effect could be related to our culture conditions and reflect delayed entry of dbcAMP into cells derived from small follicles. Support for this hypothesis can be drawn from the observation by Hoskins, Hall \& Munsterman (1975) that dbcAMP is less effective than adenyl cyclase inhibitors in stimulating cAMP-dependent activity in spermatozoa. Our result cannot be attributed to poor responsiveness of the culture or to lack of activity of the stimulants used, because similar cultures responded to PG stimulation and the dbcAMP caused immediate response in other cultures. Changes in the cell membrane are known to occur during this phase of follicle maturation (Channing \& Kammerman, 1973) and have been suggested to occur during the luteal phase (Henderson \& McNatty, 1975).

Pretreatment of cells from small follicles of mature rhesus monkeys with dbcAMP resulted in a decreased response to PGF-2 $\alpha$, although response to PGE-2 was unaltered, indicating that dbcAMP may partly block the effects of PGF- $2 \alpha$ on cells from rhesus follicles at this stage of maturation. The mechanism and significance of this inhibition is open to speculation, but the results suggest a difference in mode of action of these two PGs and that the hormonal environment of the follicle can influence its response to stimulation by PGF-2 $\alpha$, thereby accounting for some of the disparate results reported for the effect of PGF-2 $\alpha$ on progesterone synthesis.

Our results thus confirm previous observations that granulosa cells recovered from small follicles of PMSG-treated mature and immature female rhesus monkeys are able to secrete progesterone, particularly cells from mature females, and that cells recovered from larger follicles luteinize spontaneously in culture. More importantly, the results suggest that there is an increase in the capacity of cells to secrete progesterone and in the sensitivity to PG stimulation which parallels maturation of the animal, and that there is an increased responsiveness to dbcAMP which parallels maturation of the follicle. The latter effect could be the result of changing permeability of the cell membrane. Thus the stage of maturity of the follicles, and of the animal from which they were obtained, can profoundly alter the response of cell cultures to various luteotrophic stimuli, despite uniform priming in vivo. Extremely careful definition of the source of experimental material and isolation of variables is therefore necessary to resolve current questions concerning the luteolytic and/or luteotrophic properties of prostaglandins and other agents assumed to influence intracellular cAMP levels.

Supported by NIH grant No. RR00165 and Ford Foundation grant No. 690-0645A.

\section{References}

auletta, F.J., Speroff, L. \& Caldwell B.V. (1973) Prostaglandin $F_{2 \alpha}$ induced steroidogenesis and luteolysis in the primate corpus luteum. J. Clin. Endocr. Metab. 36, 405-407.

Channing, C.P. (1971) Prostaglandin stimulation of luteinization of rhesus monkey granulosa cell cultures. Biol. Reprod. 5, 87, Abstr.

Channing, C.P. (1972) Stimulatory effects of prostaglandins upon luteinization of rhesus monkey granulosa cell cultures. Prostaglandins 2, 331-350.

Channing, C.P. \& Kammerman, S. (1973) Characteristics of gonadotropin receptors of porcine granulosa cells during follicle maturation. Endocrinology 92, $531-540$.

Henderson, K.R. \& McNatty, K.P. (1975) A biochemical hypothesis to explain the mechanism of luteal regression. Prostaglandins 9, 779-797.
Hoskins, D.D., Hall, M.L. \& Munsterman, D. (1975) Induction of motility in immature bovine spermatozoa by cyclic AMP phosphodiesterase inhibitors and seminal plasma. Biol. Reprod. 13, 168-176.

Korda, A.R. Shutt, D.A., Smith, I.D., Shearman, R.P. \& LYNEHAM, R.C. (1975) Assessment of possible luteolytic effect of intra-ovarian injection of prostaglandin $\mathrm{F}_{2 \alpha}$ in the human. Prostaglandins 9, 443-449.

LiNDNer, H.R., TSAFriRi, A., Lieberman, M.E., Zor, Koch, Y., Bauminger, S. \& BarneA, A. (1974) Gonadotropin action on cultured graafian follicles: induction of maturation division of the mammalian oocyte and differentiation of the luteal cell. Recent Prog. Horm. Res. 30, 79-127.

LYNEHAM, R.C., Korda, A.R., Shutt, D.A., SMIth, I.D. \& Shearman, R.P. (1975) The effect of intra- 
uterine prostaglandin $F_{2 \alpha}$ on corpus luteum function in the human. Prostaglandins 9, 431-442.

MARsh, J.M. (1976) The role of cyclic AMP in gonadal steroidogenesis. Biol. Reprod. 14, 30-53.

Puri, C.P. \& Laumas, K.R. (1975) Dose and time dependent luteotropic and luteolytic action of prostaglandin $F_{2 \alpha}$ in the luteinized rabbit ovary. Prostaglandins 9, 675-694.

SHAIKH, A.A. (1972) Regulation of menstrual cycle and termination of pregnancy in the monkey by estradiol and PGF 2 . Prostaglandins 2, 227-233.

SHAIKH, A.A. \& KLAIBER, E.L. (1974) Effects of sequential treatment with estradiol and $\mathbf{P G F}_{2 \alpha}$ on the length of the primate menstrual cycle. Prostaglandins 6, 253-262.

ThORNEYCROFT, I.H. \& STONe, S.C. (1972) Radioimmunoassay of serum progesterone in women receiving oral contraceptive steroids. Contraception 5, 129-146.

Wright, K., Robinson, H., Collins, D.C. \& Preedy, J.R.K. (1973) Investigation of a radioimmunoassay for plasma estrone and estradiol-17ß in males and non-pregnant females. Comparison with an independent method using fluorimetry. J. clin. Endocr. Metab. 36, 165-169.

Received 22 November 1976 